\title{
The Mechanical Response of Pre-Shocked Aluminium Single Crystals
}

\author{
Jeremy Millett ${ }^{1, *}$, George. Gray III $^{2}$, Glenn Whiteman ${ }^{1}$, Saryu. Fensin ${ }^{2}$, and Gareth Owen ${ }^{1}$ \\ ${ }^{1}$ AWE plc, Aldermaston, Reading, RG7 4PR. United Kingdom \\ ${ }^{2}$ Los Alamos National Laboratory, Los Alamos, NM, 87545. USA
}

\begin{abstract}
The behaviour of metals under mechanical loading, including shock loading conditions is strongly influenced by effects such as impurity levels, grain size, initial dislocation density and texture. The work discussed here is part of a wider study on the effects of orientation of aluminium single crystals to one dimensional shock loading, including the Hugoniot Elastic Limit and spall strength. In this work, specimens with three principle directions $(<100>,<110>$ and $<111>$ ) parallel to the loading axis have been shock loaded and recovered under conditions of purely one-dimensional strain, with their post shock response monitored by quasi-static compression tests. Results show that the $<100>$ crystal demonstrates a significant degree of post shock hardening, whilst the $<111>$ crystal shows virtually none, and the $<110>$ intermediate between the two. These results are consistent with the ordering of both the HELs and spall strengths observed in a previous paper, and have been explained in terms of the Schmidt factors.
\end{abstract}

\section{Introduction}

The high strain-rate response of aluminium based alloys has been the subject of intensive study over the past decades, due to their applications as light weight armour materials, and as structural components in the aerospace industry $[1,2]$. However, such studies are often constrained to specific alloy compositions, and properties will vary significantly due to differences in dislocation density, distribution of additional phases and grain size. It is often useful to study metals in their pure form, as the results can be used to determine basic mechanical and microstructural responses without the added complication of additional microstructural features. The logical extension of this philosophy lies with the study of single crystals and assuming that the relationship between loading axis and crystal orientation is known, the generated data is more fundamental in nature and suitable for input in crystal plasticity models. In spite of this, shock data on single crystal materials is much less extensive than on polycrystalline variants, often leading to contradictory results. For example, Chen et al. [3] suggested that spall (dynamic tensile strength) was greatest in the $<100>$ direction compared to $<111>$, whilst our own measurements (including the Hugoniot Elastic Limit - HEL) [4] suggested precisely the opposite. However, the ordering of our measurements were in agreement with quasi-static testing of single crystal aluminium. Similar measurements in copper by Minich et al. [5] gave the same ordering of spall strength with orientation as Chen et al. [3], whilst measurements of the HEL in aluminium by Huang and Asay [6] reversed the ordering again. However, they were able to confirm the ordering of their results through consideration of the elastic constants. Further, this method was also used to explain the ordering of HEL versus crystal orientation in copper [7], thus showing that the mechanical response of single crystals, even in face centred cubic lattices requires more than just geometric considerations.

Much of the work on the shock behaviour of single crystals has concentrated on the mechanical response. However, to gain a full understanding, information on the microstructural response is also necessary. Follansbee and Gray [8] investigated the shock induced microstructure and quasi-static mechanical response of nickel, showing that from a resolved shear strength perspective, there was little difference in either the microstructural response (dislocation cell formation) or post shock quasi-static response, with both $<100>$ and $<111>$ orientations showing post shock hardening with little difference between the two.

In this paper, we expand on the single crystal work we previously reported on by investigating the quasistatic mechanical response of three aluminium single crystals, oriented along the three principle axes $(<100>$, $<110>$ and $<111>$.

\section{Experimental}

All shots were performed using an $80 \mathrm{~mm}$ diameter single stage gas gun, based at Los Alamos National Laboratory. Samples from each crystal orientation were shocked to $9.8 \mathrm{GPa}$ for a duration of $1 \mu \mathrm{s}$, after being cooled to $-135{ }^{\circ} \mathrm{C}$ to mimimize shock induced thermal recovery processes. Single crystal aluminium disks were 
mounted into target assemblies consisting of a nested series of rings to trap lateral momentum and plates immediately behind the specimen to mitigate the effects of spallation. Finally, a $1 \mathrm{~mm}$ cover plate at the impact face was used to absorb the small amount of shear strain generated by impact of the flyer. All parts of the target assembly apart from the single crystal specimens were made from the polycrystalline aluminium alloy 6061-T6. After separation of the specimen, it was carefully decelerated into a mixture of felt and water to avoid further deformation on recovery. More details of the recovery technique can be found in the references of Gray et al. [9-12]. After the samples had been successfully recovered, right cylinders $(5 \mathrm{~mm} \times 5 \mathrm{~mm})$ were trepanned out of the recovered disks such that the long axis was parallel to the original shock axis. Two specimens from each recovered sample were then tested in compression at $20^{\circ} \mathrm{C}$ and a strain-rate of $10^{-3} \mathrm{~s}^{-1}$.

\section{Materials}

Three bars of single crystal aluminium, ca. $50 \mathrm{~mm}$ diameter, each orientated with the long axis parallel to the three principle axes were purchased from Metal Crystals and Oxides Ltd, Cambridge, UK, with a stated angular tolerance of $\pm 1^{\circ}$. The purity was quoted at $99.999 \%$. The orientations of the single crystals were confirmed using Electron Back Scatter Diffraction, the results of which are presented in figure 1 . a)

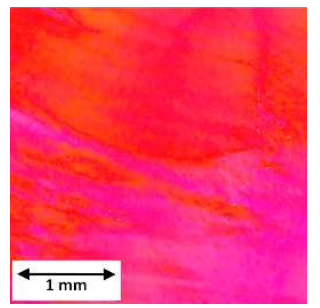

c)

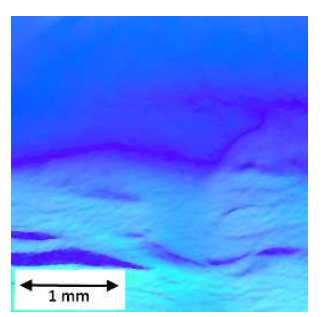

b)

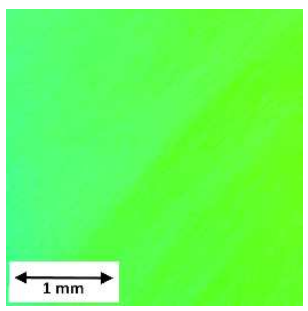

d)

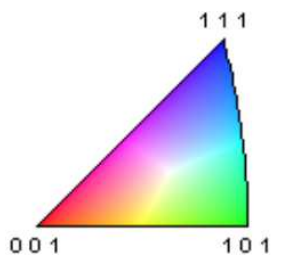

Fig. 1. EBSD micrographs of the three single crystals a) $<100>$, b) $<110>$ and c) $<111>$. d) Inverse pole figure.

The $<100>$ and $<111>$ crystals show some evidence of minor misorientations (as shown by the contrast in the EBSD images), deviating into the $<112>$ and $<212>$ directions respectively.

Sound speed measurements were made for each orientation, and the results are presented in Table 1. Note that the $\langle 110\rangle$ orientation has two distinct shear wave velocities due to the two fold rotational symmetry.
Table 1. Acoustic properties of the single crystals. Values in parenthesis have been calculated from reported single crystal elastic constants [13].

\begin{tabular}{|l|l|l|l|}
\hline Material & $<\mathbf{1 0 0}>$ & $<\mathbf{1 1 0}>$ & $<\mathbf{1 1 1}>$ \\
\hline$\rho_{0}\left(\mathrm{~g} \mathrm{~cm}^{-3}\right)$ & 2.699 & 2.699 & 2.699 \\
\hline$c_{\mathrm{L}}\left(\mathrm{mm} \mathrm{\mu s}^{-1}\right)$ & $6.40(6.29)$ & $6.44(6.44)$ & $6.49(6.49)$ \\
\hline$c_{\mathrm{S}}\left(\mathrm{mm} \mu \mathrm{s}^{-1}\right)$ & $3.22(3.24)$ & $3.24(3.24)$ & $3.01(3.04)$ \\
& & $2.95(2.93)$ & \\
& & & \\
\hline
\end{tabular}

\section{Results}

In figure 1, we present the quasi-static response (imposed strain-rate of $10^{-3} \mathrm{~s}^{-1}$ ) of the as received and shock loaded aluminium crystals.

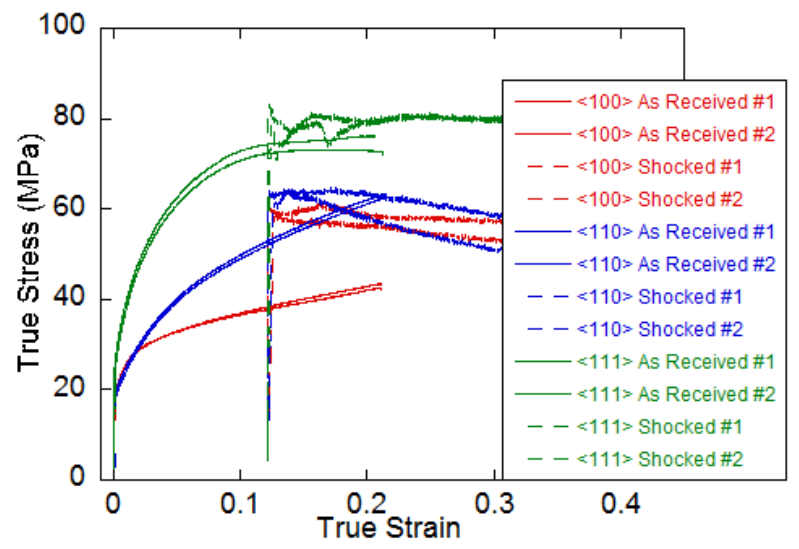

Fig. 2. True stress-strain curves for as-received and shocked $(9.8 \mathrm{GPa}, 1 \mu \mathrm{s})$ aluminium single crystals.

Note that the stress-strain curves for the shocked crystals have been displaced along the strain axis by the strain $(\varepsilon)$ imposed by the shock loading process. This has been calculated from the shock relations of aluminium [14], via the relation,

$s=\frac{4}{3} \ln \left(\frac{V}{V_{0}}\right)$

where $V_{0}$ and $V$ are the ambient and shock induced specific volumes respectively. This relation also takes into account that the strain imposed on release is effectively identical to that imposed on shock, and thus both must be accounted for in determining the applied strain [15]. These results show that strength in the as received crystals, both in terms of yield strength and flow stress increases from $<100>$ to $<110>$ with $<111>$ having the highest strength, in agreement with our previous shock loading experiments in terms of HEL and spall strength [4]. After shock loading, the $<100>$ shows the greatest level of post shock hardening, followed by $<110>$ with $<111>$ showing the least. Observed that in all cases, despite that all three orientations in their as received state show significant levels of work hardening, the shocked crystals show near zero work hardening or 
even a level of work 'softening'. Possible causes include the shocked crystals undergoing dislocation recovery during quasi-static deformation or differences in dislocation cell size according to specific orientation.

In an effort to gain a better understanding of their response to quasi-static and shock induced deformation, we have followed the methodology of Follansbee and Gray [8] by calculating the resolved shear stresses $(\tau)$ and shear strains $(\gamma)$, determined through the appropriate Schmidt factors, $M$,

$$
\tau=M \sigma \text { and } \gamma=\frac{\Xi}{M}
$$

where

$$
M=\cos \theta \cos \lambda
$$

with $\theta$ the angle between the slip plane normal and the loading axis and $\lambda$ the angle between the slip direction and the loading axis.

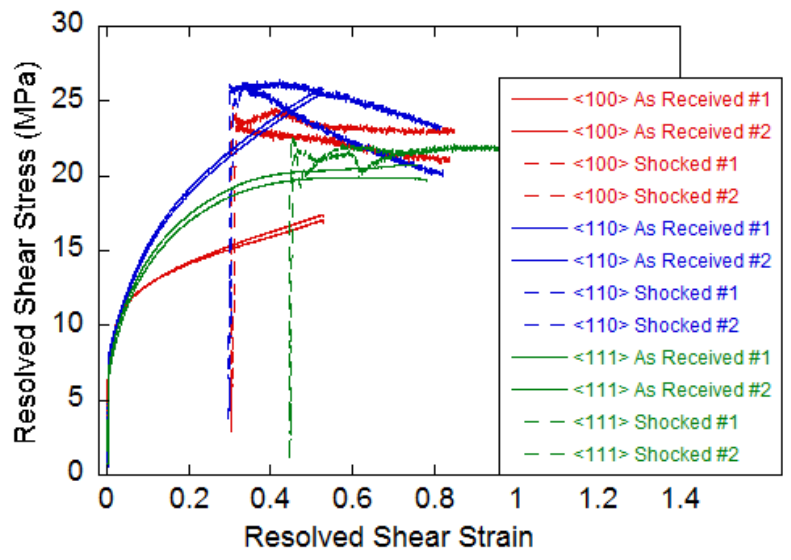

Fig. 3. Resolved shear stress-strain curves for as-received and shocked $(9.8 \mathrm{GPa}, 1 \mu \mathrm{s})$ aluminium single crystals.

After this analysis, the situation is similar, but note that the $<110>$ and $<111>$ orientations have reversed position.

\section{Discussion}

The response of aluminium single crystals to shock loading has been investigated by studying the quasistatic compression behaviour pre and post shock. From the unshocked stress-strain curves in figures 2 and 3, it can be seen that all three orientations show parabolic work hardening. This is characteristic of single crystals where plastic deformation can access more than one slip system.

Table 2. Schmidt factors for potential slip systems and their variation with loading geometry in a face centred cubic single crystal.

\begin{tabular}{|c|c|c|c|c|}
\hline & $\begin{array}{l}{[\overline{101}]} \\
{[\overline{011}]}\end{array}$ & $\begin{array}{l}1 / \sqrt{3} \\
1 / \sqrt{3}\end{array}$ & $\begin{array}{c}1 / \sqrt{2} \\
0\end{array}$ & 0 \\
\hline (111) & $\begin{array}{l}{[110]} \\
{[101]} \\
{[011]}\end{array}$ & $\begin{array}{l}1 / \sqrt{3} \\
1 / \sqrt{3} \\
1 / \sqrt{3}\end{array}$ & $\begin{array}{c}1 / \sqrt{2} \\
1 / \sqrt{2} \\
0\end{array}$ & $\begin{array}{c}0.408 \\
0.408 \\
0\end{array}$ \\
\hline$(1 \overline{1} 1)$ & $\begin{array}{l}{[110]} \\
{[101]} \\
{[011]}\end{array}$ & $\begin{array}{l}1 / \sqrt{3} \\
1 / \sqrt{3} \\
1 / \sqrt{3}\end{array}$ & $\begin{array}{c}1 / \sqrt{2} \\
1 / \sqrt{2} \\
0\end{array}$ & $\begin{array}{c}0.408 \\
0.408 \\
0\end{array}$ \\
\hline (111) & $\begin{array}{l}{[\overline{1} 10]} \\
{[\overline{1} 01]} \\
{[011]}\end{array}$ & $\begin{array}{l}1 / \sqrt{3} \\
1 / \sqrt{3} \\
1 / \sqrt{3}\end{array}$ & $\begin{array}{c}1 / \sqrt{2} \\
1 / \sqrt{2} \\
0\end{array}$ & $\begin{array}{c}0.408 \\
0.408 \\
0\end{array}$ \\
\hline \multicolumn{5}{|c|}{$<110>$} \\
\hline (111) & $\begin{array}{l}{[\overline{1} 10]} \\
{[\overline{101}]} \\
{[\overline{0} 1]}\end{array}$ & $\begin{array}{l}2 / \sqrt{6} \\
2 / \sqrt{6} \\
2 / \sqrt{6}\end{array}$ & $\begin{array}{c}0 \\
1 / 2 \\
1 / 2\end{array}$ & $\begin{array}{l}0 \\
0.408 \\
0.408\end{array}$ \\
\hline (111) & $\begin{array}{l}{[110]} \\
{[101]} \\
{[\overline{1} 1]}\end{array}$ & $\begin{array}{l}0 \\
0 \\
0\end{array}$ & $\begin{array}{c}0 \\
1 / 2 \\
1 / 2\end{array}$ & $\begin{array}{l}0 \\
0 \\
0\end{array}$ \\
\hline (11ī) & $\begin{array}{l}{[110]} \\
{[101]} \\
\text { [011] }\end{array}$ & $\begin{array}{l}0 \\
0 \\
0\end{array}$ & $\begin{array}{c}1 \\
1 / 2 \\
1 / 2\end{array}$ & $\begin{array}{l}0 \\
0 \\
0\end{array}$ \\
\hline (11ī) & $\begin{array}{l}{[\overline{1} 10]} \\
{[101]} \\
\text { [011] }\end{array}$ & $\begin{array}{l}2 / \sqrt{6} \\
2 / \sqrt{6} \\
2 / \sqrt{6}\end{array}$ & $\begin{array}{c}0 \\
1 / 2 \\
1 / 2\end{array}$ & $\begin{array}{l}0 \\
0.408 \\
0.408\end{array}$ \\
\hline \multicolumn{5}{|c|}{$<111>$} \\
\hline (111) & $\begin{array}{l}{[110]} \\
{[\overline{101}]} \\
{[011]}\end{array}$ & $\begin{array}{l}1 \\
1 \\
1\end{array}$ & $\begin{array}{l}0 \\
0 \\
0\end{array}$ & $\begin{array}{l}0 \\
0 \\
0\end{array}$ \\
\hline (111) & $\begin{array}{l}{[110]} \\
{[101]} \\
{[011]}\end{array}$ & $\begin{array}{l}1 / 3 \\
1 / 3 \\
1 / 3\end{array}$ & $\begin{array}{c}2 / \sqrt{6} \\
2 / \sqrt{6} \\
0 \\
\end{array}$ & $\begin{array}{l}0.272 \\
0.272 \\
0\end{array}$ \\
\hline (111) & $\begin{array}{l}\text { [110] } \\
{[101]} \\
{[011]}\end{array}$ & $\begin{array}{l}1 / 3 \\
1 / 3 \\
1 / 3\end{array}$ & $\begin{array}{l}2 / \sqrt{6} \\
0 \\
2 / \sqrt{6}\end{array}$ & $\begin{array}{l}0.272 \\
0 \\
0.272\end{array}$ \\
\hline (11 $\overline{1})$ & $\begin{array}{l}{[110]} \\
{[101]} \\
{[011]}\end{array}$ & $\begin{array}{l}1 / 3 \\
1 / 3 \\
1 / 3\end{array}$ & $\begin{array}{l}0 \\
2 / \sqrt{6} \\
2 / \sqrt{6}\end{array}$ & $\begin{array}{l}0 \\
0.272 \\
0.272\end{array}$ \\
\hline
\end{tabular}

\begin{tabular}{|l|l|l|l|l|}
\hline \multicolumn{5}{|c|}{$<100>$} \\
\hline $\begin{array}{l}\text { Slip } \\
\text { Plane }\end{array}$ & $\begin{array}{l}\text { Slip } \\
\text { Direction }\end{array}$ & $\operatorname{Cos} \theta$ & $\operatorname{Cos} \lambda$ & $M$ \\
\hline (111) & {$[110]$} & $1 / \sqrt{3}$ & $1 / \sqrt{2}$ & 0.408 \\
& & & & 0.408 \\
\hline
\end{tabular}

This is illustrated in table 2, where for each loading orientation in this investigation, the Schmidt factors $(M)$ for each possible slip system have been calculated.

Where $M=0$, this is an indication that either the slip plane or slip direction is orientated at $90^{\circ}$ to the loading axis, and hence shear cannot be activated on that slip system. From table 2 , it can be seen that $<100>$ has the greatest number of available slip systems (eight), followed by $<111>$ with six and finally $<110>$ with four, where it can be seen that this ordering is reflected in the resolved shear stress-strain curves presented in figure 3 . 
However, if we now consider the level of post-shock hardening, it can be seen that whilst $<100>$ displays significant levels, $<110>$ shows only a small amount and $<111>$ very little at all. Taking a wider look at fcc metals in general, post shock hardening can be effected by a number of factors. Significant levels of post shock hardening are seen in metals with moderate to high SFEs, such as copper [16], nickel [8] or aluminium alloys $[17,18]\left(78,128\right.$ and $166 \mathrm{~mJ} \mathrm{~m}^{-2}$ respectively [19]), but if the SFE is reduced by alloying, such as copper-aluminium alloys [20-22], or austenitic stainless steels [23], post shock hardening can be reduced to zero or even induce a reduction in post shock strength. This is explained in terms of the separation of partial dislocations; the lower the SFE, the wider the partial spacing, and the lower their mobility and ability to overcome obstacles by climb or cross slip. This can often promote deformation by twinning, hence reducing the dependence on dislocation based deformation further. Alternatively, hardening can also be reduced by changing the microstructure in the same material, for example in the aluminium alloy 6061, where post shock hardening is significant in the solution treated, single phase state, it reduces to near zero when the material receives an aging treatment [18] that creates a distribution of nano sized $\mathrm{Mg}_{2} \mathrm{Si}$ particles throughout the microstructure that act as an impediment to dislocation motion. Therefore, as a global statement, reducing the dislocation mobility in polycrystalline fcc metals and alloys reduces the level of post shock hardening. Whilst these microstructural concepts clearly cannot be applied to variations in crystal orientations, the concept of effective dislocation mobility can. We have already used the available slip systems to explain the ordering of the resolved shear stresses in the unshocked material. However, we also need to consider the effects of the Schmidt factor itself. The deformation in fcc crystals is at its easiest when $M=0.5$ [19]. In the case of the $<100>$ and $\langle 110\rangle$ orientations, $M$ is close to 0.5 at 0.408 , although as $\langle 110\rangle$ only has half the number of operative slip systems as $<100>$, this orientation is harder. This also manifests in the post shock response. $<100>$ has a typical high SFE fcc response in that it displays a high level of post shock hardening. This is due to the very high strain-rates imposed during shock loading. In effect, the dislocation velocity in insufficient to accommodate the applied deformation during shock, and hence the material has to respond by generating extra dislocations. Reloading quasi-statically after therefore shows the higher yield strength once the imposed shock strain has been accounted for. In the case of $\langle 110\rangle$, the fewer available slip systems result in a lower dislocation generation (compared to $\langle 100\rangle$, although a small, yet definite level of hardening is still observed. In the case of $\langle 111\rangle$, it would be expected that with six available slip systems, it should exhibit behaviour intermediate between $\langle 100\rangle$ and $<110\rangle$. However, it can be seen from table 2 that the Schmidt factor is the lowest of all three orientations at 0.272 . In this case, although there are six active slip systems, they are less favourably orientated, and the required shear stresses will be higher. As such the ability to build up dislocation density, even during shock loading will be greatly reduced, hence the extremely limited post shock hardening seen in figures 2 and 3 .

An important point that needs addressing is the behaviour of the post shock quasi-static stress-strain curves after yield. In previous materials such as copper [16] or nickel [8], the pre-shocked stress strain curves show very little work hardening than their unshocked counterparts. This was explained in terms of the extreme build up in dislocation density during shock loading that precluded significant dislocation generation post shock. We would suggest that the same process is occurring in single crystal aluminium, but further factors affect the final response. Note that in both the $<100>$ and $<110>$ orientations, the post shock response shows a degree of softening, whilst the $<111>$ orientation is essentially flat. We believe that this may be evidence of recovery processes in the $\langle 100\rangle$ and $\langle 110\rangle$ orientations, in that on quasi-static deformation of the shocked samples, dislocations have the potential to either re-align themselves into low angle boundaries or annihilate on an individual basis. In the case of $\langle 111\rangle$, the dislocation build up during shock is not great enough to give a sufficiently high dislocation density that could support recovery on reloading. However, we acknowledge that without supporting evidence from transmission electron microscopy, these possibilities remain speculative.

Finally, the strong variation between level of post shock hardening and crystal orientation in aluminium shown in this study appears to be at odds with similar experiments in nickel, performed by Follansbee and Gray [8], where they showed that when examined on a resolved shear stress basis, the effects of orientation (and grain size) where almost zero. However, Meyers [19] has pointed out that the critically resolved shear stress in nickel is effectively orientation independent, which assuming that the same does not apply in aluminium, would explain the differences between nickel and aluminium.

\section{Conclusions}

A series of experiments have been performed to study the effects of single crystal orientation on the post shock mechanical response of aluminium. After shock loading to $9.8 \mathrm{GPa}$ for one microsecond, at $-135{ }^{\circ} \mathrm{C}$, the $<100>$ orientation was shown to show the greatest degree of post shock hardening, followed by $<110>$ with $<111>$ showing the least. We have suggested that a combination of available slip systems, combined with the Schmidt factors are responsible for these differences; $<100>$ has eight operative slip systems, with a Schmidt factor of 0.408 which allows for ease of dislocation motion and generation during shock loading. Whilst $<110\rangle$ also has a Schmidt factor of 0.408 , the fact that it will have only four available slip systems will somewhat compromise its ability to generate dislocations during shock loading and hence reduce the post shock hardening. Finally, in $<111>$, although there are six active slip systems, the low Schmidt factor $(\mathrm{M}=0.272)$ will further hinder dislocation generation, hence resulting in the lowest 
degree of shock hardening of all three orientations. We have also observed that in the $<100>$ and $<110>$ orientations that a degree of work softening has occurred. It has been suggested that the high dislocation build up during shock loading, combined with deformation during quasi-static reloading will result in recovery, thus accounting for the reduction in stress after yield in the shocked samples. In the case of $\langle 111\rangle$, the high Schmidt factor prevented a high enough dislocation density to build up during shock loading to trigger recovery during subsequent quasi-static deformation. Microstructural examination is underway to investigate further.

CBritish Crown Owned Copyright 2018/AWE

We would like to thank Carl Trujillo and Mike Lopez of Los Alamos National Laboratories for performing the shock and quasi-static loading experiments. We are also grateful to $\mathrm{X}$. Yan, S. Pickering, S.S. Doak and G.D. West of Loughborough University, UK for the EBSD work.

\section{References}

1. J.M. Boteler, D.P. Dandekar. J Appl Phys.100, 054902 (2006)

2. Z. Rosenberg, G. Luttwak, Y. Yeshurun, Y. Partom. J Appl Phys.54, 2147 (1983)

3. X. Chen, J.R. Asay, S.K. Dwivedi. J Appl Phys.99, 023528 (2006)

4. G.D. Owen, D.J. Chapman, G. Whiteman, S.M. Stirk, J.C.F. Millett, S. Johnson. J Appl Phys.122, 155102 (2017)

5. R.W. Minich, J.U. Cazamias, M. Kumar, A.J. Schwartz. Met Mat Trans A.35A, 2663 (2004)

6. H. Huang, J.R. Asay. J Appl Phys.100, 043514 (2006)

7. O.E. Jones, J.D. Mote. J Appl Phys.40, 4920 (1969)

8. P.S. Follansbee, G.T. Gray III. Int J Plast.7, 651 (1991)

9. G.T. Gray III. In: Schmidt SC, Johnson JN, Davison LW, editors. Shock Compression of Condensed Matter - 1989. Amsterdam: North-Holland; 1990. p. 407.

10. G.T. Gray III. In: Asay JR, Shahinpoor M, editors. High-Pressure Shock Compression of Solids. New York: Springer-Verlag; p. 187 (1991)

11. G.T. Gray III. In: Meyers MA, Murr LE, Staudhammer KP, editors. Shock-wave and highstrain-rate phenomena in materials. New York: Marcel Dekker; p. 899 (1992)

12. N.K. Bourne, G.T. Gray III. Proc R Soc A.461, 3297 (2005)

13. J.F. Thomas. Phys Rev.175, 955 (1968)

14. S.P. Marsh. Shock Hugoniot Data. Los Angeles: University of California Press (1980)

15. M.A. Meyers. Dynamic Behavior of Materials. New York: Wiley-Interscience (1994)

16. G.T. Gray III, C.E. Morris. Journal de Physique IV.Colloque C3, 191 (1991)

17. G.T. Gray III. Acta Metall.36, 1745 (1988)
18. J.C.F. Millett, N.K. Bourne, M.Q. Chu, I.P. Jones, G.T. Gray III, G. Appleby-Thomas. J Appl Phys.108, 073502 (2010)

19. M.A. Meyers, K.K. Chawla. Mechanical Behaviours of Materials. Cambridge: Cambridge University Press (2009)

20. A. Rohatgi, K.S. Vecchio. Mater Sci Engng.A328, 256 (2002)

21. A. Rohatgi, K.S. Vecchio, G.T. Gray III. Met Mat Trans A.32A, 135 (2001)

22. A. Rohatgi, K.S. Vecchio, G.T. Gray III. Acta Mater.49, 427 (2001)

23. Q. Xue, G.T.Gray III, B.L. Henrie, S.A. Maloy, S.R. Chen. Metall Mater Trans A.36, 1471 (2005) 
